University of San Diego

Digital USD

2011-03-01

\title{
Relationship between Self-Stigma and Personal Empowerment among People Who have Severe Mental IIIness
}

Diane Fischer Hickman PhD

University of San Diego

Follow this and additional works at: https://digital.sandiego.edu/dissertations

Part of the Nursing Commons

\section{Digital USD Citation}

Fischer Hickman, Diane PhD, "Relationship between Self-Stigma and Personal Empowerment among People Who have Severe Mental IIIness" (2011). Dissertations. 405.

https://digital.sandiego.edu/dissertations/405

This Dissertation: Open Access is brought to you for free and open access by the Theses and Dissertations at Digital USD. It has been accepted for inclusion in Dissertations by an authorized administrator of Digital USD. For more information, please contact digital@sandiego.edu. 


\section{UNIVERSITY OF SAN DIEGO}

Hahn School of Nursing and Health Science

DOCTOR OF PHILOSOPHY IN NURSING

RELATIONSHIP BETWEEN SELF-STIGMA AND PERSONAL

EMPOWERMENT AMONG PEOPLE WHO HAVE SEVERE MENTAL ILLNESS

By

Diane Fischer Hickman

A dissertation presented to the

FACULTY OF THE HAHN SCHOOL OF NURSING AND HEALTH SCIENCE

UNIVERSITY OF SAN DIEGO

In partial fulfillment of the

requirements for the degree

DOCTOR OF PHILOSOPHY IN NURSING

March 2011

Dissertation Committee

Jane M. Georges, PhD, RN, Chairperson

Ann M. Mayo, RN; DNSc

Ruth N. Grendell, DNSc, RN 


\section{ABSTRACT}

The purpose of this study was to examine the relationship between self-stigma of mental illness and personal empowerment among people who have a severe mental illness. It had been hypothesized that self-stigma of mental illness and personal empowerment are at opposite end of a continuum. As such, individuals who perceive themselves in a stigmatized manner tend to reciprocally perceive themselves as being relatively powerless, rather than having a strong sense of personal empowerment. Likewise, individuals who perceive themselves as having a relatively strong sense of personal empowerment tend to experience a low degree of self-stigma.

To test this hypothesis, a quantitative research study was conducted to examine the relationship between self-stigma of mental illness and personal empowerment. The Spearman rho statistical procedure was performed to test the strength of the relationship between these two variables. The Self-stigma of Mental Illness scale was used to measure self-stigma of mental illness and the Making Decisions Empowerment scale was used to measure personal empowerment. Eighty four research participants completed these two instruments, plus a demographic questionnaire that was utilized to describe the sample population. The correlation between the two variables, self-stigma of mental illness and personal empowerment revealed a large, inverse, statistically significant relationship, $n(84)=-.562, p<.01$. Overall, participants with higher scores on the self-stigma of mental illness scale had lower scores on the making decisions, personal empowerment scale, and vice versa. These findings provide meaningful data that can be used in the context of the mental health recovery process. Becoming empowered is an important aspect of mental health recovery.

Implications for further studies include interventions to enhance personal empowerment. Of particular interest to the researcher is the concept of healing relationships, in which the 
characteristics of relationships may be essentially helpful or hurtful. In the context of mental health recovery and healing relationships as an intervention, there is much to be explored and studied about the art and science of healing relationships. 


\section{DEDICATION}

To my beloved husband Jim Hickman, whose infinite love and support enabled me to accomplish my heartfelt desire to earn a $\mathrm{PhD}$ in Nursing. Jim and I travelled this academic journey side-by-side, hand-in-hand. He listened to all my ideas that were stimulated by my coursework, read all my papers, and functioned as a research assistant during my entire doctoral program. Jim truly deserves an honorary doctoral degree. Furthermore, our relationship with each other exemplifies the best of healing relationships that I've addressed in this dissertation.

To my father Jack Fischer, who would have been so proud of my accomplishment. He instilled in me the importance of education and inspired me to be the lifelong learner I've become.

To my mother Sigrid Fischer, who has given her love and support immeasurably throughout my life. She continues to give of herself even now, at the age of ninety. It is my joy to experience her expressions of pride in my accomplishment. 


\section{ACKNOWLEDGEMENTS}

As I reflect on my marvelous journey toward receiving my $\mathrm{PhD}$ in Nursing, it gives me great joy to formally thank my dissertation chairperson, Dr. Jane M. Georges for her infinite inspiration, guidance and support that she poured into me so lovingly. I feel exceedingly privileged and honored to have been under her tutelage, starting with my first semester course, PHDN 601 - Logics of Inquiry, and concluding with this doctoral dissertation. Thank you Dr. Georges. May you receive exponential amounts of blessings and love that you have given to me, in the capacity as my doctoral dissertation chairperson.

I'm delighted to formally acknowledge and thank my dissertation committee member, Dr. Ann M. Mayo, for all her enthusiastic support of my developing ideas, theoretical concepts, and my data analyses. Dr. Mayo's consistent, positive, and nurturing ways of relating to me inspired me toward excellence. Special credit is due to Dr. Mayo for working intensively with me on the final draft of my dissertation. Dr. Mayo imparted into me the critical knowledge and skill of writing a formal, academic research paper. Everything I learned from Dr. Mayo from the exciting process of preparing my dissertation proposal, through the writing of the final draft of my dissertation are valuable skills that will serve me well throughout my career as a Nursing Science researcher.

Words are hardly sufficient to express the depth of my gratitude to Dr. Ruth N, Grendell, who became my academic adviser, mentor and confidant during my time in the BSN program at Point Loma Nazarene University. She and I immediately established a close connection, which we continue to enjoy today. Dr. Grendell's belief in me and her limitless support empowered me to successfully complete the MSN program at Point Loma Nazarene University. As I prepared 
myself to apply for the $\mathrm{PhD}$ in Nursing at the University of San Diego, Dr. Grendell helped pave the way by provided a reference for me. Dr. Grendell continued to extend her academic and social support for me during my $\mathrm{PhD}$ in Nursing program, which culminated with her being a member of my dissertation committee. Thank you, Dr. Grendell, for all your support and love throughout my nursing education, both academically and personally since 1998 . 


\section{Table of Contents}

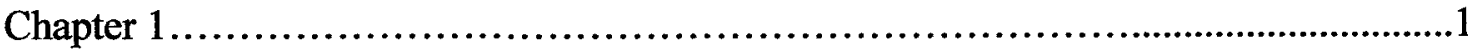

Relationship between Self-stigma and Personal Empowerment................1

Background and Significance............................................

Disempowering process of self-stigma.............................2

Righteous indignation and protective factors........................2

Self-stigma as a Barrier to Mental Health Recovery $\ldots \ldots \ldots \ldots \ldots \ldots \ldots \ldots \ldots \ldots . . . \ldots$

Statement of Purpose........................................................

Research Questions....................................................4

Key Concepts and Definitions..............................................4

Mental Health Recovery..........................................4

Empowerment........................................................5

Self-stigma of Mental Illness........................................5

Severe Mental Illness.............................................6

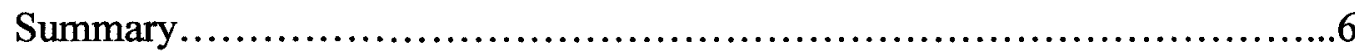

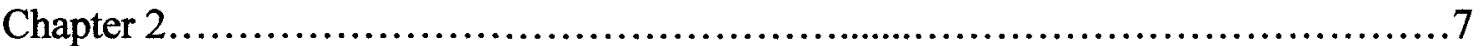

Relevant Literature Review and Conceptual Framework......................

Relevant Literature Review......................................7

Self-stigma.............................................7

Empowerment..........................................8

Gaps in the Relevant Literature...........................................

Relationship between Self-stigma and Personal Empowerment..........9

Mediating Factors................................................. 10 
Philosophical Underpinnings of the Mental Health Recovery Model............11

Mental Health Recovery and Healing Relationships..........................11

Healing Relationships in the Context of Mental Health Recovery.............12

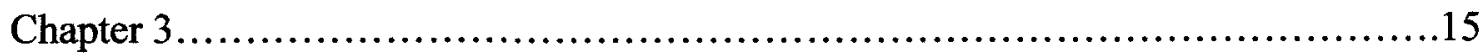

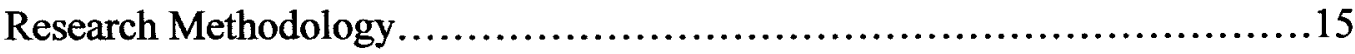

Research Design.........................................................15

Data Collection Instruments........................................... 15

The Self-stigma of Mental Illness scale (SSMI) .....................16

SSMI scale reliability and construct validity..................16

Personal empowerment (The Making Decisions Empowerment scale)..17

Reliability and validity of the MDE scale......................18

Demographic data............................................... 18

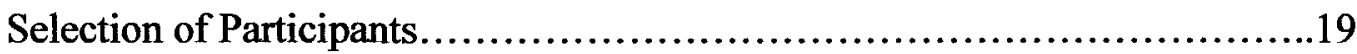

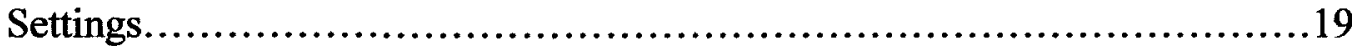

Characteristics of facilities..........................................19

Sites where data collection was conducted..........................20

Sampling Procedures and Criteria...........................................20

Inclusion criteria................................................20

Determination of ability to provide informed consent.................21

Exclusion criteria................................................21

Data Collection Procedures..............................................21

Data Analysis Procedures...........................................23

Considerations Regarding Human Subjects...............................23 


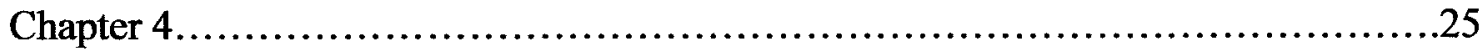

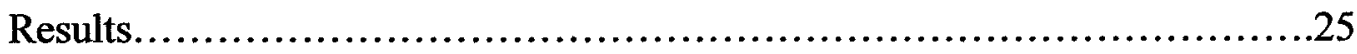

Descriptive Statistics....................................................25

Description of Sample Population...................................26

Description of the Self-stigma of Mental Illness Scale Scores............27

Description of the Making Decisions Empowerment Scale Scores......27

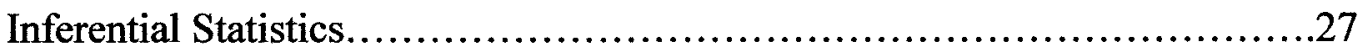

Summary of Significant Findings.......................................28

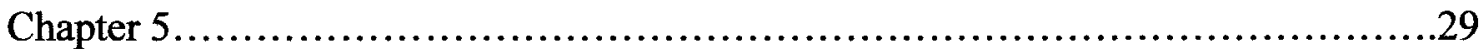

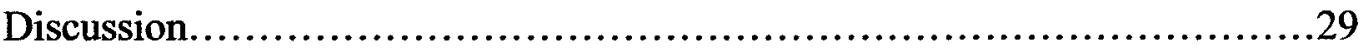

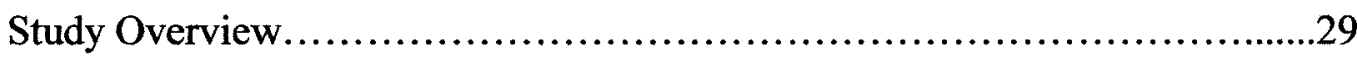

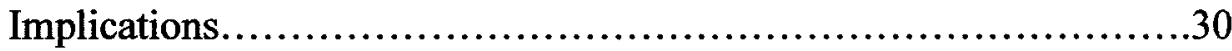

Direct relevance of this study .................................30

Limitations of this Study ...........................................30

Significance of this Study for Future Nursing Research................31

Proposed Focus of Future Research Regarding Healing Relationships..........32

Relevant Outgrowth..................................................

Significance of this Study for Future Nursing Theory and Foundational Concepts 33

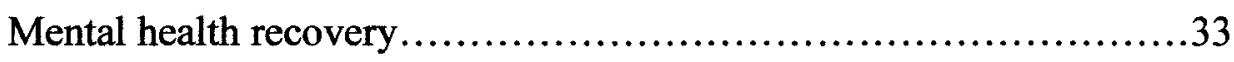

Mental illness stigma, self-stigma, and personal empowerment..........34

Beyond the barrier of stigma.............................................

Potential Role for Nursing in the Field of Mental Health Recovery....................35

Returning to our roots............................................... 
Therapeutic relationship..........................................35

Mental Health Recovery and Power Relations...................................36

Egalitarian verses non-egalitarian relationships.......................36

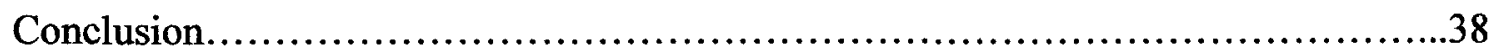

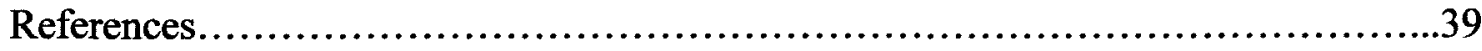




\section{List of Tables}

Description of Sample Population...........................................26

Demographic Table...................................................26

Description of the Self-stigma of Mental Illness Scale Scores.....................27

Apply Scale Total Score...........................................27

Description of the Making Decisions Empowerment (MDE) scale Scores............27

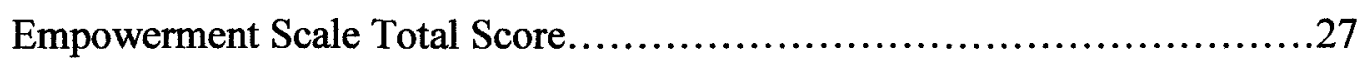




\section{List of Illustrations}

Figure 1: Relationship between Self-stigma and Personal Empowerment..............10

Figure 2: Conceptualization of Healing Relationships and Mental Health Recovery....12 


\section{List of Appendices}

1. University of San Diego, Institutional Review Board Approval Document

2. Appendix A: Correspondence with Dr, E. Sally Rogers, granting permission to use her Making Decisions Empowerment (MDE) Scale.

3. Appendix B: Correspondence with Dr. Patrick Corrigan, granting permission to use his Self-stigma of Mental Illness (SSMI) Scale. 


\section{Chapter 1}

\section{Relationship between Self-stigma and Personal Empowerment}

Researchers have claimed that self-stigma and personal empowerment are at opposite ends of the same continuum (Watson, Corrigan, Larson, \& Sells, 2007). Based upon an exhaustive literature review no empirical studies were found to support this assumption. Although new research pertaining to mental health recovery is ongoing, a formal scientific connection between the concepts of self-stigma as a barrier to mental

health recovery and empowerment as a critical component of mental health recovery had yet to be established. The intention of this research study was to tie together these concepts in order to develop a theoretical framework on which to build more advanced nursing science pertaining to mental health recovery.

\section{Background and Significance}

Self-stigma and personal empowerment are thought to be opposite ends of a continuum, relative to mental health recovery. People who perceive themselves negatively due to having a mental illness experience a high degree of self-stigma, while people who have a positive self image in spite of having a mental illness experience a high degree of personal empowerment (Watson et al., 2007). Although this supposition has been generally accepted (Corrigan \& Watson, 2002; Corrigan, 2004; 
Corrigan \& Calabrese, 2005; Corrigan, Watson, \& Barr, 2006; Fung, Tsang, Corrigan, Lam, \& Cheng, 2007; Rüsch, Angermeyer, \& Corrigan, 2005; Rüsch, Lieb, Bohus, \& Corrigan, 2006; Rogers, Chamberlin, Ellison, \& Crean, 1997; Rogers, Teague, Lichenstein, Campbell, Lyass, Chen et al., 2007; Verhaeghe, Bracke, \& Bruynooghe, 2008; Watson et al., 2007), it had not been empirically tested. Therefore scientific validation that self-stigma and personal empowerment are at opposite ends of the same continuum was warranted.

Disempowering process of self-stigma. The concept of self-stigma is quite complex. It is characterized by a 3 tiered process that influences an individual's perception of himself or herself. According to Watson et al. (2007) the development of self-stigma involves stereo-type awareness, stereo-type agreement, and self-concurrence. Stereo-type awareness is explained by the modified labeling theory (Kroska \& Harkness, 2006; Link, Struening, Cullen, Shrout, \& Dohrenwend, 1989). It involves having a basic knowledge of mental illness stigma, which in and of itself is not sufficient for the development of self-stigma. Stereo-type agreement is the next prerequisite for self-stigma to occur. Finally, in order for an individual to experience self-stigma he or she must not only agree that the stereotypical social views of mental illness are true, he or she also believes that these derogatory perceptions are true about himself or herself. Watson et al. (2007) add that embracing self-stigma on a personal level results in significant losses of self-esteem and self-efficacy.

Righteous indignation and protective factors. Not everyone who has a serious mental illness develops the disabling effects of self-stigma. Some people respond to the awareness of socially constructed stigma with righteous indignation, which provides the 
impetus to overcome the limitations that are commonly associated with symptoms of mental illness (Watson et al., 2007). Additionally, research has revealed that the affiliation with a group of people who have mental illness can be the means by which individuals are able to perceive themselves in a neutral light rather than a negative manner (Rogers, et al., 1997; Rogers, et al., 2007; Watson, et al., 2007; Watson \& Larson, 2006).

\section{Self-stigma as a Barrier to Mental Health Recovery}

It is widely recognized that self-stigma is a major barrier to mental health recovery and facilitating empowerment is accepted as a vital component of mental health recovery (Anthony, 1993; Brown, Shepherd, Merkle, Wituk, \& Meissen, 2008; Caltaux, 2002; Corrigan \& Watson, 2002; Corrigan \& Kleinlein, 2005; Fung, Tsang, \& Corrigan, 2008; Fung, et al., 2007; Gallo, 1994; Greene-Shortridge, Britt, \& Andrew, 2007; Jensen \& Wadkins, 2007; Linhorst, Hamilton, Young, \& Eckert, 2002; Lundberg, Hansson, Wentz, \& Björkman, 2008; Masterson \& Owen, 2006; Perese, 2007; Rogers et al., 1997; Rogers et al., 2007; SAMHSA, 2006; Smith, 2000; Tal, Roe, \& Corrigan, 2007; Verhaeghe, et al., 2008; Vogel, Wade, \& Haake, 2006; Watson \& Larson, 2006; Werner, Aviv, \& Barak, 2008). Both the concepts and phenomenon of self-stigma and personal empowerment among people who have severe mental illnesses are complex. The more that is understood about the relationship between self-stigma and personal empowerment, the more effective mental health recovery interventions may become.

\section{Statement of Purpose}

The overall purpose of this study was to examine the relationship between selfstigma and personal empowerment among people who have severe mental illness. 
The specific aims of this study were to:

1. Describe relevant demographic variables pertaining to people who have severe mental illness;

2. Examine the relationship between self-stigma and personal empowerment among people in this population;

\section{Research Questions}

The research questions addressed in this study were:

1. What are the characteristics of relevant demographic variables among people with severe mental illness?

2. What is the relationship between self-stigma and personal empowerment in this population?

\section{Key Concepts and Definitions}

\section{Mental Health Recovery}

Mental health recovery is recognized as a process in which individuals experience a growing ability to live a full and meaningful life in spite of having a severe mental illness. The following is a widely recognized definition of mental health recovery that was established by the Substance Abuse and Mental Health Services Administration (SAMHSA) and the Interagency Committee on Disability Research in partnership with six other federal agencies during the National Consensus Conference on Mental Health Recovery and Mental Health Systems Transformation on December 16-17, 2004 (SAMHSA, 2006): 
Mental health recovery is a journey of healing and transformation enabling a person with a mental health problem to live a meaningful life in a community of his or her choice while striving to achieve his or her full potential.

This is the operational definition of mental health recovery used in this research study.

\section{Empowerment}

Empowerment has been recognized as a critical component of mental health recovery for many years. Daniel B. Fisher, M.D., Ph.D., founder and CEO of the National Empowerment Center, used the term empowerment in the following context (Fisher, 1994 a):

People with psychiatric disabilities have articulated a model of recovery that encourages their empowerment by emphasizing consumer defined goals, liberty, self-control of symptoms, peer support, elimination of discrimination, and provision of adequate material and social supports.

Empowerment was identified as one of the key components of mental health recovery during the National Consensus Conference on Mental Health Recovery and Mental Health Systems Transformation. Since then the process of becoming personally empowered is widely accepted as a critical aspect of mental health recovery. An operational definition of empowerment is the sense of having personal ability and authority to make decisions about choices and take action regarding ones' own lifestyle.

\section{Self-stigma of Mental Illness}

The concept and operational definition of self-stigma of mental illness is described as a limitation experienced by individuals who have a severe mental illness due to their personal belief that the socially constructed concept of mental illness stigma is 
accurate and true about them. Research pertaining to mental illness stigma has been the work of Patrick Corrigan, PsyD., the principal investigator of several federally funded studies pertaining to psychosocial rehabilitation, team leadership, and consumer operated services. Six years ago, Corrigan became principal investigator of the Chicago Consortium for Stigma Research (CCSR), the only NIMH-funded research center examining the stigma of mental illness. This research study examining the relationship between self-stigma and personal empowerment among people who have severe mental illness was inspired by Corrigan's research.

\section{Severe Mental Illness}

For the purposes of this study, "severe mental illness" was defined as having a Diagnostic and Statistical Manual of Mental Disorders IV (DSM IV) Axis I diagnosis that constitutes a serious mental illness, such as schizophrenia, schizoaffective disorder, bipolar disorder or major depressive disorder.

\section{Summary}

This research study was designed to quantitatively determine the relationship between self-stigma and personal empowerment among people who have a severe mental illness. Two established instruments were utilized to measure self-stigma and personal empowerment respectively. The relationship between self-stigma and personal empowerment was statistically analyzed to validate the assumption that self-stigma and personal empowerment are at opposites ends of same continuum (Watson et al., 2007). 


\section{Chapter 2}

\section{Relevant Literature Review and Conceptual Framework}

\section{Relevant Literature Review}

Self-stigma. The term and concept of self-stigma originated within the context of the joint work of Amy C. Watson, Patrick Corrigan, Jonathon E. Larson, and Molly Sells at the University of Illinois at Chicago, and the Joint Research Programs in Psychiatric Rehabilitation, Illinois Institute of Technology, University of Chicago. According to Watson et al., (2007) self-stigma is characterized by a 3 tiered process that influences an individual's perception of himself or herself. The following figure by Watson et al., entitled Theoretical Model of Self-Stigma, diagrammatically conceptualizes the development of self-stigma,

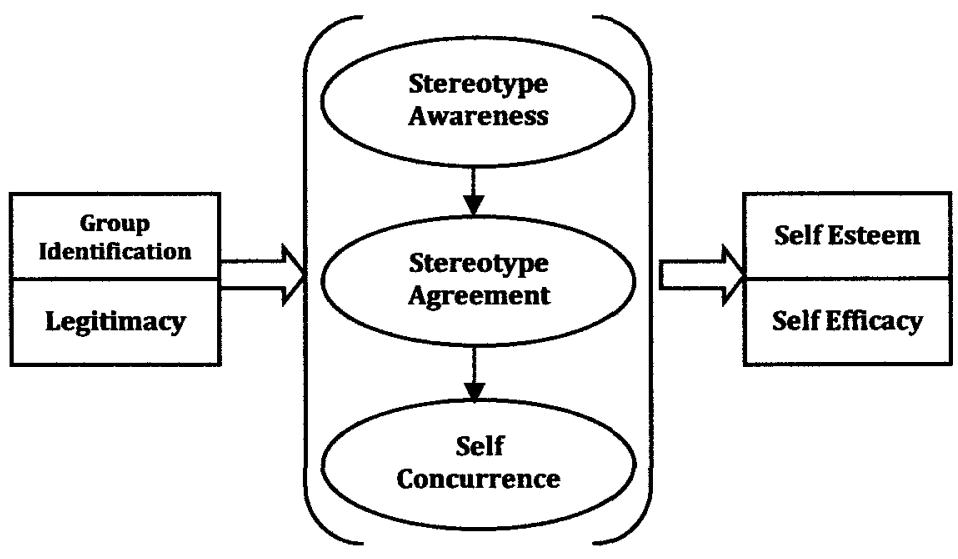

(Watson et al, 2007, p. 2). 
The development of self-stigma involves stereo-type awareness, stereo-type agreement, and self-concurrence. Stereo-type awareness is explained by the modified labeling theory (Kroska \& Harkness, 2006; Link et al., 1989). It involves having a basic knowledge of mental illness stigma, which in and of itself is not sufficient for the development of self-stigma. Stereo-type agreement is the next prerequisite for self-stigma to occur. Finally, in order for an individual to experience self-stigma he or she must not only agree that the stereotypical social views of mental illness are true, he or she also believes that these derogatory perceptions are true about himself or herself. Watson et al., (2007) add that embracing self-stigma on a personal level results in significant losses of self-esteem and self-efficacy.

\section{Empowerment}

Empowerment is recognized as a central theme and concept related to mental health recovery. According to Andrews, Motes, Floyd, Fler, \& Fede (2005):

Empowerment is defined in many different ways. Some definitions, for example, focus on psychological attributes, whereas others incorporate an ideology that stresses reduction of consumer reliance on traditional mental health services. One constant theme within most definitions is the importance of consumer and family involvement in making decisions about their services.

Consistent throughout the relevant literature pertaining to mental health recovery, it is recognized that being empowered is an important intervention, becoming empowered is a process, and empowerment is a significantly desirable outcome (Andrews et al., 2005; Baker \& Buchanan-Barker, 2004; Brown et al., 2008; Corrigan, 2004; Corrigan, Faber, Rashid, \& Leary, 1999; Crane-Ross, Lutz, \& Dee, 2006; Deegan, 1997; Dixon et al., 
2004; Falk-Rafael, 2001; Finfgeld-Connett, 2008; Fisher, 1994 a; Fisher, 1994 b; Fisher, 2003; Frain, Tschopp, \& Bishop, 2009; Fulton, 1997; Green, et al., 2008; Hansson \& Björkman, 2005; Linhorst et al., 2002; Lundberg et al., 2008; Mancini, 2007; Masterson \& Owen, 2006; McCubbin, 2001; Padgett \& Henwood, 2009; Rogers et al., 1997; Rogers, et al., 2007; Rüsch et al., 2005; Rüsch et al., 2006; Schiff, 2004; Sells, Borg, Marin, Mezzina, Topor, \& Davidson, 2006; Shanley \& Jubb-Shanley, 2007; Straughan \& Buckenham, 2006; Till, 2007; Watson \& Larson, 2006; Wehmeyer, 2004; WongMcDonald, 2007).

\section{Gaps in the Relevant Literature}

The basis for this research study was the glaring absence of information that connects the concept of self-stigma of mental illness with the concept of personal empowerment. According to the relevant literature there is a general acceptance that selfstigma and empowerment are on opposite ends of a continuum (Watson, et al., 2007). An exhaustive literature review revealed no scientific evidence that self-stigma and empowerment are correlated in this context. A review of the relevant literature revealed that the nature of relationships between mental health service providers and service recipients significantly impacts the mental health recovery process, although this notion is implied rather than formally recognized.

\section{Relationship between Self-stigma and Personal Empowerment}

This study is embedded in a broader conceptual model pertaining to power relations and healing relationships. The research question regarding the relationship between self-stigma and personal empowerment viewed diagrammatically is as follows: 


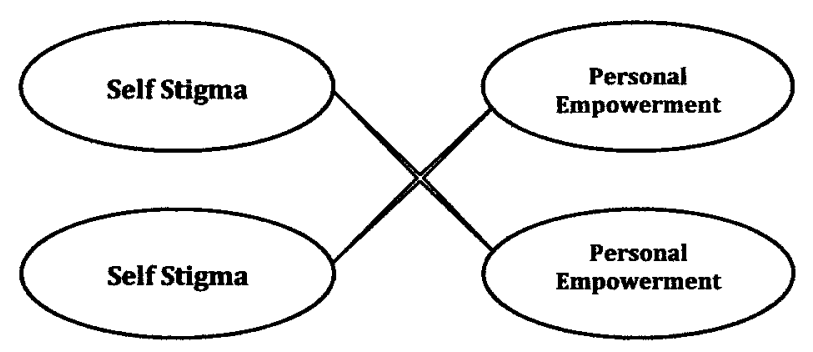

\section{Figure 1: Relationship between Self-stigma and Personal Empowerment}

Self-stigma and personal empowerment are thought to be opposite characteristics, relative to mental health recovery. People who perceive themselves negatively due to having a mental illness experience a high degree of self-stigma, while people who have a positive self-image in spite of having a mental illness experience a high degree of personal empowerment (Watson, et al., 2007).

\section{Mediating Factors}

A critical factor that significantly impacts the mental health recovery potential for people who have severe mental illness is the nature of the power relations between mental health service providers and service recipients (Fardella, 2008). Reflecting on Foucault's philosophy of power relations, Fardella (2008) addressed the necessity of egalitarian relationships between healthcare professionals and clients in order for mental health recovery to occur. Furthermore, Fardella (2008) recommended, "that the individual emphasis on self-care and the co-operative potential of the recovery model would be enhanced by the attentive inclusion of Habermas' discourse ethics and its contribution towards promoting and protecting the non-coercive, dialogical resolution of differences between clients and professionals" (p. 112). 


\section{Philosophical Underpinnings of the Mental Health Recovery Model}

A comprehensive overview of the mental health recovery model with specific relevance to the relationship between self-stigma and personal empowerment may be conceptualized by examining the discourse between mental healthcare providers and service recipients. Essentially, when these the relationships between healthcare professionals and clients are characterized by egalitarian discourse, clients may experience a sense of personal empowerment. Conversely, when mental healthcare providers assert the traditional authoritarian-type power over mental healthcare recipients, their clients assume a subordinate sick role, consistent with the concept of self-stigma. (Fardella, 2008)

\section{Mental Health Recovery and Healing Relationships}

Consistent with the philosophies of Foucault and Habermas as elucidated by Fardella (2008), relationships between mental health service providers and service recipients may perpetuate recovery or may foster submissive dependence (Bledsoe, Lukens, Onken, Bellamy, \& Cardillo-Geller, 2008). As such, the conceptual underpinning of this research study is a synthesis of theories drawn from Hilegard Peplau, Michel Foucault and Jurgen Habermas. Peplau's Theory of Interpersonal Relations explains the role of the psychiatric nurse as an instrument of healing for the patient. According to Peplau, the relationship between the nurse and the patient promotes healing (Gastmans, 1998). Similarly to Peplau's theory, the theories Foucault and Habermas highlight the importance of egalitarian, respectful discourse, which is consistent with the mental health recovery model. (Fardella, 2008) 


\section{Healing Relationships in the Context of Mental Health Recovery}

Ultimately, according to the relevant literature and the conceptual framework of this research study, healing relationships are an essential component in the process of mental health recovery. Healing relationships are characterized by supportive, respectful attitudes, behaviors and communication discourse. Conversely, relationships that convey disrespectful attitudes, behaviors and communication hinder mental health recovery. Healing relationships promote personal empowerment that is necessary for mental health recovery (Bledsoe, et al., 2008). Essentially, the concepts of egalitarian power relations and ethical discourse are central to the theoretical underpinnings of this research study (Fardella, 2008). A diagrammatic representation of this conceptual framework is as follows:

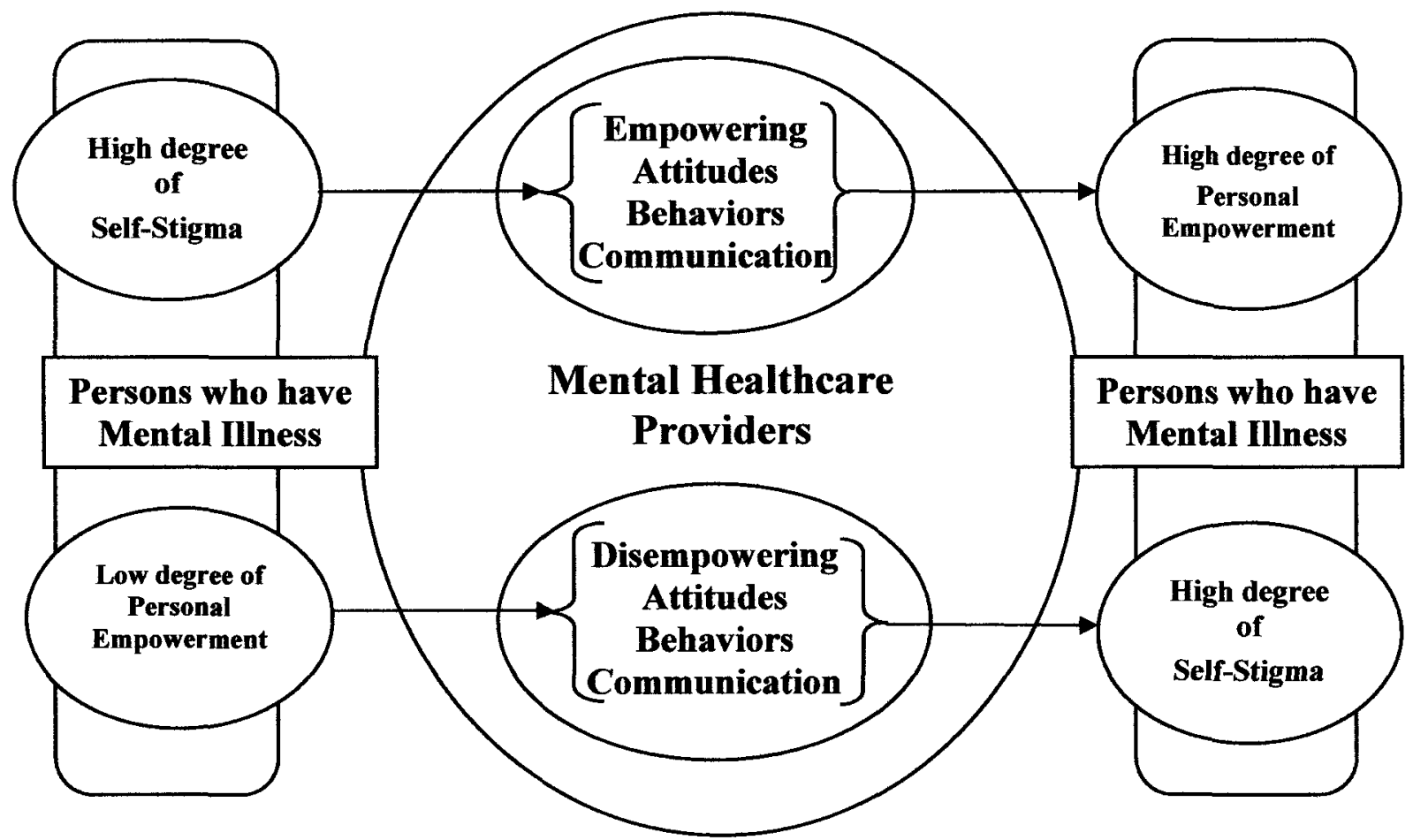

Figure 2: Conceptualization of Healing Relationships and Mental Health Recovery 


\section{Conceptualization of healing relationships in the context of mental health}

recovery. The column on the left represents people who have a mental illness. As a result of the mental illness people experience a high degree of self-stigma and a low degree of personal empowerment. The large oval in the center represents the full complement of mental health providers. Some mental health clinicians, consciously or unconsciously have stigmatizing attitudes, beliefs and discourse about mental illness. In spite of the role of mental health clinician, these people express their stigmatizing, disempowering attitudes, behaviors and communication, verbally as well as non-verbally. As a result they perpetuate and even exacerbate their clients' sense of self-stigma. Conversely, the mental health clinicians who express themselves with respectful, egalitarian mannerisms and discourse convey a sense of empowerment in the context of their interactions with their clients.

This conceptual framework is not limited to mental health providers. These empowering and disempowering attitudes, behaviors and communication exist between all people in every situation in which people interact. Often it is the unconscious ways we relate to each other that have significant impact. For the purpose of this study this depiction is limited to interactions between people who have a known mental illness and people in professional clinical positions, who are relied upon to assist their clientele. Relative to the concept of healing relationships, it becomes incumbent on the person in the position of healer to address his or her own attitudes, behaviors, and communication such that healing occurs in the context of the relationships with clients. This is the antithesis of traditional therapeutic alliance, conceptually. Traditionally, the focus of the relationship between the healthcare provider and the client is changing the client in some 
way. Conceptually, within the context of the healing relationship, it is understood that respectful, egalitarian attitudes, behaviors and communication, on the part of the clinician, will promote healing of the client. Therefore, as healers, it is our responsibility to examine ourselves with the intent to change our own attitudes, behaviors, and communications so that we may became genuine conduits of healing. 


\section{Chapter 3}

\section{Research Methodology}

This chapter presents a description of the research methodology including study design, sample and sampling, data collection procedures, instrumentation, data analysis, and the protection of human subjects.

\section{Research Design}

A quasi-experimental, quantitative research design was utilized to conduct this study. A bivariate correlation statistical procedure was used to calculate the relationship between self-stigma and personal empowerment.

Study Hypothesis:

There is no relationship between self-stigma and personal empowerment.

\section{Data Collection Instruments}

Two quantitative assessment instruments were used to collect data about selfstigma and personal empowerment, the Self-Stigma of Mental Illness Scale (SSMI) and the Making Decisions Empowerment (MDE) scale respectively. The selection of these two instruments for this study was determined based on the information obtained from an exhaustive literature review on the subjects of self-stigma of mental illness and personal empowerment related to mental health recovery. 
The SSMI instrument. The Self-Stigma of Mental Illness scale was developed by Patrick Corrigan, PsyD. This instrument is designed to measure the four significant components of self-stigma, which are stereotype awareness, stereotype agreement, selfconcurrence and self-esteem decrement. The original scale included 15 items in each subscale. The revised version has ten items, an adjustment made that increased internal consistency and reliability (Corrigan et al., 2006). Written permission to use this instrument was obtained from Dr. Corrigan. Correspondence from Dr. Corrigan granting permission to use the SSMI is in the appendix of this dissertation.

SSMI scale reliability and construct validity. In their article "The Self-Stigma of Mental Illness: Implications for Self-Esteem and Self-Efficacy" Corrigan, et al., (2006) presented the reliability and internal construct validity of the SSMI scale as follows (p. 878):

TABLE 1. Cronbach's Alphas and Test-Retest Reliabilities for the Original and Revised Versions of the Four Levels of the Self-Stigma of Mental Illness Scale

\begin{tabular}{|l|c|c|c|}
\hline Self-Stigma of Mental IIIness Subscale & Version & Cronbach's Alpha & Test-Retest Reliability \\
\hline Stereotype awareness & original & 0.85 & 0.72 \\
\hline & revised & 0.91 & 0.73 \\
\hline Stereotype agreement & original & 0.64 & 0.62 \\
\hline & revised & 0.72 & 0.68 \\
\hline Self-concurrence & original & 0.72 & 0.72 \\
\hline & revised & 0.81 & 0.82 \\
\hline Self-esteem decrement & original & 0.87 & 0.75 \\
\hline & revised & 0.88 & 0.78 \\
\hline
\end{tabular}

Table 2 provides summary data of the inter-correlations among the four SSMIS subscales as follows (p. 880): 
TABLE 2. Cronbach's Alphas for the Four Self-Stigma Scales. Pearson's Product Moment Correlations among Four Self-Stigma Scales. Correlations between Self-Stigma Scales and Measures of Self-Esteem, Self-Efficacy, Righteous Anger, and Depression

\begin{tabular}{|l|c|c|c|c|}
\hline & $\begin{array}{c}\text { Stereotype } \\
\text { Awareness }\end{array}$ & $\begin{array}{c}\text { Stereotype } \\
\text { Agreement }\end{array}$ & $\begin{array}{c}\text { Self- } \\
\text { Concurrence }\end{array}$ & $\begin{array}{c}\text { Self-Esteem } \\
\text { Decrement }\end{array}$ \\
\hline Cronbach's Alpha & 0.89 & 0.80 & 0.72 & 0.81 \\
\hline Stereotype Awareness & 1.00 & 0.11 & 0.15 & 0.11 \\
\hline Stereotype Agreement & & 1.00 & $0.55^{* * *}$ & $0.47^{* * *}$ \\
\hline Self-concurrence & & & 1.00 & $0.84^{* * *}$ \\
\hline Self-esteem decrement & & & & 1.00 \\
\hline General Self-efficacy (SASES) & $-0.39^{* *}$ & -0.05 & - & $-0.47^{* * *}$ \\
\hline Self-esteem (RA) & $-0.39^{* *}$ & -0.16 & $-0.46^{* * *}$ & $-0.48^{* * *}$ \\
\hline & & & & $0.42^{* * * *}$ \\
\hline
\end{tabular}

Note. ES = Empowerment Scale; RA = Rosenberg Assessment Scale; SASES = Sherer and Adams SelfEfficacy Scale; BPRS = Brief Psychiatric Rating Scale; ${ }^{\star p}<.05 ;{ }^{\star \star} p<.01 ;{ }^{\star \star} p<.001$

Accordingly Corrigan et al., (2006) describes:

As expected, stereotype awareness (representing the person's perceptions of public stigma) was not significantly associated with any of the other three levels of the model. Significant correlations $(p<.001)$ with moderate effect sizes were found between stereotype agreement and the indices representing selfconcurrence and self-esteem decrement. Self-concurrence and self-esteem decrement were highly correlated. (p. 879)

Personal empowerment scale. The Making Decisions Empowerment scale was constructed under the direction of E. Sally Rogers, Sc.D. of the Center for Psychiatric Rehabilitation at Boston University, by people who were actively using mental health services at six self-help centers in six states (Rogers et al., 1997). In her article entitled, Effects of participation in consumer-operated service programs on both personal and organizationally mediated empowerment: Results of multisite study, Rogers et al., (2007) provided the following description of her empowerment scale: 
The Making Decisions Empowerment (MDE) scale is a 28-item instrument designed to measure subjective feelings of empowerment in which respondents' rate statements on a 4-point scale (1 - "Strongly Agree" and $4=$ "Strongly Disagree"). Most of the items indicate greater empowerment; individual scale values for these items are reversed (subtracted from 5) so that higher scores are more favorable, and responses are then summed across items. The scale taps the domains of self-efficacy, perceived power, optimism about and control over the future and community activism. (p. 787-8)

Dr. Rogers provided permission for the MDE to be used for this study. Correspondence with Dr. Rogers is in the appendix of this dissertation.

Reliability and validity of the MDE scale. According to Rogers et al. (2007) the instrument "has good consistency and internal reliability as well as good factorial and known groups' validity. For this study, we calculated the internal consistency for this instrument using baseline data as 0.81 (Cronbach $a$ )" (p. 788).

Demographic data. In addition to the SSMI and the MDE questionnaires, the following demographic data was collected:

1. gender

2. ethnicity

3. age

4. primary psychiatric diagnosis

5. age at onset of illness

6. number of hospitalizations for mental illness, if any This information was used to describe the sample population. 


\section{Selection of Participants}

Initially, a sample size calculation was conducted that determined for power of .80 , alpha level of 0.05 , and assuming a medium effect size (.3), the total required sample size was 84 .

Subsequently a sample size of 84 participants for this study was recruited from three residential facilities within the County of San Diego, in California, where residents met the inclusion criteria for this study. Access to the sample population was obtained by requesting permission from the organizational leadership to approach potential participants who resided at the facilities where participant recruitment was conducted. Letters of permission to approach and recruit research participants at these facilities were obtained from appropriate officials in advance.

\section{Settings}

Characteristics of the facilities. The residential facilities where the data collection was conducted were characterized as supportive housing specifically for people who have severe mental illnesses. These facilities were designed to provide assistance with meals and other aspects of daily living in a structured, stable, consistent manner. Of the three facilities where data was collected for this study, the first was a board and care (B\&C), the second was an independent living facility (ILF), and the third was a transitional housing facility.

As background, in California, board and care (B\&C) facilities for people who have severe mental illnesses are licensed by the state to care for people with mental illnesses. The services provided included housing, food, laundry, and management of medications, as well as other individualized needs. Independent living facilities (ILFs) for 
people who have severe mental illnesses are similar to board and care facilities, but they are not state regulated, which means that ILFs are not required to meet state licensure criteria. As a result, there are differences between individual ILFs regarding services provided.

Sites where data collection was conducted. Pertaining to the facilities at which data was collected for this study, the ILF was one of the more structured and well supervised ILFs in the San Diego area. Therefore the B\&C and ILF used in this study were very similar. The only significant difference was that the residents of the ILF were required to be able to manage their own medications with minimal staff supervision, rather than having their medications managed for them. Both the $\mathrm{B} \& \mathrm{C}$ and the ILF facilities provided permanent housing, where people could reside indefinitely. The third facility where data was collected was a transitional housing facility, where individuals could reside for up to two years. All residents at this facility had current problematic addiction disorders, as well as other severe mental illnesses for which they were receiving recovery oriented, supportive services. All the participants from each of the three facilities, the B\&C, the ILF, and the transitional housing facility met the inclusion criteria for this study.

\section{Sampling Procedures and Criteria}

Inclusion criteria. The inclusion criteria for participants in this study were consistent with those utilized by expert researchers in related studies. Participants were required to have Diagnostic and Statistical Manual of Mental Disorders IV (DSM IV) Axis I diagnosis that constitutes a serious mental illness, such as schizophrenia, schizoaffective disorder, bipolar disorder or major depressive disorder. A diagnosis of 
substance abuse, unless it was a co-occurring diagnosis did not meet the inclusion criteria. In addition to having a serious and persistent mental illness, participants had to be currently actively involved with a clinical mental health treatment provider, or have had access to psychiatric and mental health services during their involvement in the study. All participants had to have been at least eighteen years of age, English speaking, and able to provide informed consent.

Determination of ability to provide informed consent. This study met the criteria of minimal risk (UCSD, n.d.). As background, the regulatory definition of minimal risk is "the probability and magnitude of physical or psychological harm that is normally encountered in the daily lives or in the routine medical, dental, or psychological examination of healthy persons" (NIH, 2005). Any study involving no more than minimal risk does not require an explicit assessment of decisional capacity (UCSD, n.d.).

Exclusion criteria. Individuals who did not meet the inclusion criteria as well as those who were not able to fully participate in the data collection process at the time of the data collection were not included in the study. To fully participate in the data collection process individuals were required to answer all the questions on each of the three questionnaires, including the demographic questionnaire, the Self-Stigma of Mental Illness scale (SSMI), and the Making Decisions Empowerment (MDE) scale.

\section{Data Collection Procedures}

Data was collected from 84 participants, each of whom reported that they had a severe mental illness such as schizophrenia, schizoaffective disorder, bipolar disorder, major depressive disorder, or post-traumatic stress disorder (PTSD). In addition to the researcher, research assistants were used to collect data. To ensure reliability of data, the 
training of the research assistants consisted of an overview of the study, and explanations about the consent form, the demographic questionnaire, the SSMI and the MDE instruments. Instructions about how to administer the data collection procedures without influencing the participants' answers to the questions on the research instruments were also included in the training.

The researcher and qualified research assistants met with prospective research participants at their respective residential facilities. Interested individuals who met the inclusion criteria were given an informed consent form and the three questionnaires that were used to collect the data; the Demographic Data Questionnaire and of the two established survey instruments entitled the Self-Stigma of Mental Illness scale (SSMI) and the Making Decisions Empowerment (MDE) scale. Initially the informed consent form was read and explained to each interested person, after which each individual was asked to sign the form. The consent form and each of the questionnaires are included in the appendix of this dissertation.

Once the participant had signed the consent form, the researcher or one of the research assistants provided explanations about each of the three questionnaires. Participants were asked to mark a response to each question on each of the three questionnaires. Most participants did not indicate that they needed or wanted any further explanation of the questions, while some preferred to complete the questionnaires with the assistance of one of the research team members. Assistance was carefully provided in a manner in which participants were able to answer the questions, without any guidance as to how questions were to be answered. Participants who found that some of the questions were too difficult to understand in order to provide an answer for each question 
were allowed to terminate their involvement in the data collection process. Incomplete sets of data were not included in the study, only fully completed data sets were included. All of this was done explicitly in accordance with permission granted by the leadership of each facility at which participants were recruited, as well as the data collection criteria approved of by the University of San Diego IRB.

\section{Data Analysis Procedures}

Initially, descriptive statistics were calculated for the relevant demographic characteristics pertaining to the sample population. Subsequently, a bivariate correlation statistical procedure was conducted to determine the relationship between self-stigma and personal empowerment. For all tests the significance level was set at 0.05 . It was expected to be found that a high degree of self-stigma would be reciprocally related to a low degree of personal empowerment. Conversely, low degree of self-stigma was expected to correlate with a high degree of personal empowerment.

\section{Considerations Regarding Human Subjects}

This study was specially designed to minimize potential risks for the participants. The primary concern regarding this vulnerable population relative to this research study was that participants may experience some difficulty thinking about and discussing the symptoms of the illness from which they suffer. Some people may be particularly sensitive about issues related to their self-concept. In order to provide optimal protection from emotional distress, all participants were required to have access to appropriate psychiatric, mental health services. This was specifically delineated within the inclusion criteria of this study and approval was obtained by the University of San Diego IRB to conduct the study in this manner. Additionally all participants were offered the 
opportunity to obtain information about available resources for them to discuss and process their thoughts, feelings and concerns that may surface during or as a result of the research questions which they were asked. A potential benefit that may have occurred for participants in this study is the development of increased personal insight. This could possibly enhance their sense of personal empowerment and subsequently facilitate their mental health recovery process. 


\section{Chapter 4}

\section{Results}

The overall purpose of this study was to examine the relationship between selfstigma and personal empowerment among people who have severe mental illness. The specific aims of this study were to 1) describe relevant demographic variables pertaining to people who have severe mental illness and, 2) examine the relationship between selfstigma and personal empowerment among people in this population.

\section{Descriptive Statistics}

\section{Research Aim \#1}

In order to address Specific Aim \#1, descriptive statistics were calculated for demographic data, to include means, median scores, modes, and ranges of current ages, age at onset of the primary psychiatric diagnosis, and the number of psychiatric hospitalizations pertaining to the sample population, as shown in the demographics table below. 
Description of Sample Population

Demographics

\begin{tabular}{|c|c|c|c|c|c|c|}
\hline & & $\begin{array}{l}\text { Percent } \\
\text { (n) }\end{array}$ & $\begin{array}{l}\text { Mean } \\
\text { (SD) }\end{array}$ & Median & Mode & Range \\
\hline Age & & & $\begin{array}{c}47.33 \\
(9.081)\end{array}$ & 50 & 50 & $21-64$ \\
\hline Gender & $\begin{array}{l}\text { Males } \\
\text { Females }\end{array}$ & $\begin{array}{l}84.5 \\
(71) \\
15.5 \\
(13) \\
\end{array}$ & & & & \\
\hline Ethnicity & $\begin{array}{l}\text { Caucasian } \\
\text { African-American } \\
\text { Hispanic } \\
\text { Asian-Pacific Islander } \\
\text { American Indian/Alaska Native }\end{array}$ & $\begin{array}{l}65.5 \\
(55) \\
13.1 \\
(11) \\
11.9 \\
(10) \\
6.0 \\
(5) \\
3.6 \\
(3)\end{array}$ & & & & \\
\hline $\begin{array}{l}\text { Primary } \\
\text { Psychiatric } \\
\text { Diagnosis }\end{array}$ & $\begin{array}{l}\text { Schizophrenia } \\
\text { Schizoaffective disorder } \\
\text { Bipolar disorder } \\
\text { Major depressive disorder } \\
\text { PTSD } \\
\text { ADHD } \\
\text { Missing data }\end{array}$ & $\begin{array}{l}27.4 \\
(23) \\
13.1 \\
(11) \\
21.4 \\
(18) \\
31.0 \\
(26) \\
1.2 \\
(1) \\
1.2 \\
(1) \\
4.8 \\
(4)\end{array}$ & & & & \\
\hline Age of onset & & & $\begin{array}{c}24.54 \\
(11.043)\end{array}$ & 25 & 30 & $7-48$ \\
\hline $\begin{array}{l}\text { \# psychiatric } \\
\text { hospitalizations }\end{array}$ & & & $\begin{array}{c}6.27 \\
(8.467)\end{array}$ & 3 & 0 & $0-52$ \\
\hline
\end{tabular}




\section{Description of the Self-stigma of Mental Illness Scale Scores}

The self-stigma of mental illness scores were obtained by summing the items from the Apply Scale of the Self Stigma of Mental Illness scale instrument, which was indicative of the individual's perceived sense of self-stigma. Scores from the 84 participants in this study are summarized in the table below.

\section{Apply Scale Total Score}

\begin{tabular}{|c|c|c|c|c|c|}
\hline $\begin{array}{c}\text { Mean } \\
\text { (SD) }\end{array}$ & Median & Mode & Range & Minimum & Maximum \\
\hline $\begin{array}{c}28.24 \\
(15.74)\end{array}$ & 22.50 & 18.00 & 77.00 & 10.00 & 87.00 \\
\hline
\end{tabular}

\section{Description of the Making Decisions Empowerment (MDE) scale Scores}

The empowerment scale score was obtained by summing the items from the Making Decisions Empowerment (MDE) scale instrument, which is indicative of the individual's perceived sense of personal empowerment. Scores from the 84 participants in this study are summarized in the table below.

\section{Empowerment Scale Total Score}

\begin{tabular}{|c|c|c|c|c|c|}
\hline $\begin{array}{c}\text { Mean } \\
\text { (SD) }\end{array}$ & Median & Mode & Range & Minimum & Maximum \\
\hline $\begin{array}{c}2.79 \\
(.312)\end{array}$ & 2.75 & 2.71 & 2.29 & 1.14 & 3.43 \\
\hline
\end{tabular}

\section{Inferential Statistics}

\section{Research Aim \#2}

In order to achieve Specific Aim $\# \mathbf{2}$ and the primary null hypothesis (no relationship between self-stigma and personal empowerment) the Spearman's rho correlation was conducted since the data was non-normally distributed. This specific statistical procedure was calculated to determine the relationship between self-stigma of 
mental illness and personal empowerment. The correlation between the two variables, self-stigma of mental illness and personal empowerment revealed an inverse statistically significant relationship. The correlation between self-stigma of mental illness and personal empowerment is a large and statistically significant, $n(84)=-.562, p<.01$.

Overall, participants with higher scores in self-stigma had lower scores in personal empowerment and vice versa.

\section{Summary of Significant Findings}

Data analysis from this study reveals that there is a strong inverse relationship between self-stigma of mental illness and personal empowerment. The relationship is negatively correlated, such that individuals who perceive a high degree of self-stigma perceive a low degree of personal empowerment, while individuals who perceive a low degree of self-stigma perceive a high degree of personal empowerment. These findings demonstrated significance and therefore the null hypothesis was not supported. 


\section{Chapter 5}

\section{Discussion}

\section{Study Overview}

This study about the relationship between self-stigma and personal empowerment among people who have severe mental illness was a logical outgrowth from the existing body of knowledge regarding self-stigma of mental illness and personal empowerment, among this population. The specific aims of this study were to describe relevant demographic variables and to examine the relationship between self-stigma and personal empowerment, among people who have severe mental illness. No other study has quantitatively examined the relationship between self-stigma of mental illness and personal empowerment. Prior to this study, it had been generally accepted that selfstigma and personal empowerment were at opposite ends of a continuum, such that people who experience a high degree of self-stigma have a low degree of personal empowerment, while people who have a high degree of personal empowerment have a low degree of self-stigma (Watson et al., 2007). The results of this study provide quantitative data, which confirms that there is a relationship between self-stigma of mental illness and personal empowerment among people who have severe mental illness. 
Additionally, this relationship is inverse, which supports one portion of the conceptual model; specifically, that when this inverse relationship is in place, it likely may exist in the context of disempowering environments.

\section{Implications}

Direct relevance of this study. Self-stigma of mental illness and personal empowerment, in and of themselves, have little relevance. The results of this study are only relevant within the context of mental health recovery. The most direct relevance pertaining to the results of this study is the knowledge that it is possible for people to experience a sense of personal empowerment, in spite of having a severe mental illness. Since generalized stigma and self-stigma of mental illness continue to impede mental health recovery, it is essential that the enhancement of personal empowerment, as indicated in the other portion of the conceptual model, becomes a purposeful, vital goal within the mental health recovery process.

In order for this goal to become actualized, it will be necessary for people to become educated about the negative effects of mental illness stigma and positive outcomes of becoming empowered, relative to mental health recovery. This by no means is a simple process, since mental illness stigma is still so pervasive throughout American society and across international boundaries. However, it is likely that through research studies such as this one, beliefs about mental illness and mental health recovery may be transformed.

\section{Limitations of this Study}

The limitations of this study pertain to the collection of demographic data. All the demographic data was self-reported, rather than incorporating information from medical 
record documentation, about psychiatric diagnoses, age at onset of illness, and number of hospitalizations for mental illness. Therefore, the demographic data may not be congruent with documentation of psychiatric histories in medical records. Additionally, the gender distribution within the sample population is related to the overall ratio of males $(85 \%)$ to females (15\%) within the respective facilities, rather than the ratio of males to females who have a severe mental illness, according to the National Institute of Mental Health (NIMH) statistics (NIMH, 2010).

The rationale for having collected only self-reported demographic data was to honor the privacy of study participants, in accordance with Health Insurance Portability and Accountability Act (HIPAA). While the subjective nature of the demographical data presents an imperfect depiction of the population of people who have a severe mental illness, it does not diminish the meaningful results of this study. In fact, all the data collected in this study was subjective in nature.

\section{Significance of this Study for Future Nursing Research}

This study affirmed that there is an inverse relationship between self-stigma of mental illness and personal empowerment, as the literature indicated. The subsequent line of inquiry that would benefit nursing and health science as a whole would be future studies that explain how to increase the sense of personal empowerment for people who have mental illness. In keeping with the strong tradition of nurse theorists who have contributed so much regarding caring relationships, it would be of great interest to explore the characteristics of interpersonal relationships that promote healing. Conceptually, this could lead to a mid-range theory entitled healing relationships. 


\section{Proposed Focus of Future Research Regarding Healing Relationships}

The study of healing relationships would focus on the psychodynamics pertaining to the attitudes, behaviors and conversations in which mental health recovery may occur. This includes attitudes, behaviors and conversations of clinicians, rather than exclusively focusing on these characteristics of clients. This is significantly different from existing theories and clinical interventions. Implicit in the emerging theoretical framework of healing relationships is the fact that no one is fully healed; we are all in the process of self-actualization (Maslow, 1943).

While future nursing research may focus on the role of nurses in the context of healing relationships, there is room for broader investigation about the characteristics and dynamics of relationships, in which healing occurs. For some, healing occurs in the context of relationships within families, friends, mentors, teachers, as well as relationships with nurses and other healthcare providers. By extending the theoretical framework and scientific investigation regarding healing relationships beyond the scope of nursing science and practice, the theory of healing relationships may become a nursing theory that has interdisciplinary impact.

\section{Relevant Outgrowth}

An outgrowth of this study that particularly captured the researcher's interest is twofold. Firstly, an obvious next logical step of scholarly inquiry would be to focus future research on interventions that promote mental health recovery; in particular to examine ways in which to increase personal empowerment for people who have mental illness. Secondly, through the course of conducting and exhaustive literature review for the this research study, it became clear that now is the opportune time for nurse scientists 
to build on existing theories, toward the development of an interdisciplinary, mid-range theory, regarding interpersonal relations that facilitate healing. The following is a brief discourse that addresses foundational concepts related to mental health recovery, within an historical context of existing theories and research. It is presented, in order to provide a framework for future nursing research and theory development.

\section{Significance of this Study for Future Nursing Theory and Foundational Concepts}

Most studies on mental health recovery have been conducted by psychologists who tend to focus on therapeutic modalities that promote empowerment for people who have mental illness. As a result, there has been little foundational work to support the science of mental health recovery in terms of healing relationships. This study has many foundational implications for defining concepts leading to theory.

Mental health recovery. The first and most frequently referenced article pertaining to mental health recovery is the seminal work of Dr. William A. Anthony, entitled Recovery from mental illness: The guiding vision of the mental health service system in the 1990s (Anthony, 1993). Since then, researchers and clinicians have struggled with the concept and definition of mental health recovery (Roberts \& Wolfson, 2004). Ironically, it is the stigma about mental illness by mental health professionals that has been the biggest barrier for the reform of mental health services. In an effort to assist with the process and move forward, the Substance Abuse and Mental Health Services Administration (SAMHSA) issued the National Consensus Statement on Mental Health Recovery, which defined and explained the concepts regarding mental health recovery (SAMHSA, 2006). During that same year, from those early beginnings, the concepts for this research study took root. 
Mental illness stigma, self-stigma, and personal empowerment. Within the same period of time, Dr. Patrick Corrigan, distinguished Professor of Psychology and Associate Dean for Research at the Illinois Institute of Technology, became the principal investigator of federally funded studies pertaining to stigma of mental illness and empowerment. It is his work that inspired this research study. Most intriguing was Dr. Corrigan's recognition that there is a linear relationship between self-stigma of mental illness and the perception of personal empowerment, with self-stigma at one end of a continuum and personal empowerment at the other end (Watson, et al., 2007). Although this was a logical assumption, it had not been empirically tested. Hence this research study was developed to provide statistical validation about the relationship between selfstigma of mental illness and personal empowerment, all of which has been described within the context of this dissertation.

Beyond the barrier of stigma. By the time this research study was taking shape, it became clear that becoming empowered could diminish the harmful effects of selfstigma (Crane-Ross et al., 2006; Frain et al., 2009; Linhorst et al., 2002; Lundberg et al., 2008; Masterson \& Owen, 2006; Watson \& Larson, 2006). Research has been conducted and results published that support the notion that people who have mental illness tend to experience harmful effects of mental illness stigma, both from others as well as selfstigmatization. Additionally, the literature reflects that it is important to nurture a sense of personal empowerment as a means to promote mental health recovery. The work of psychologists has had the greatest influence in this regard. Furthermore the medical model has dominated the therapeutic arena during the past century, as noted by registered nurses Shanley and Jubb-Shanley, of University College Dublin (Shanley \& Jubb- 
Shanley, 2007). While the growing body of knowledge about mental health recovery is proliferating, nurse researchers and clinicians have been mostly silent.

\section{Potential Role for Nursing in the Field of Mental Health Recovery}

Return to our roots. Things have changed drastically for nursing since the times of Dorothea Dix (1802 -1887), Clara Barton (1821-1912), Lillian Wald (1867-1940), and Hildegard Peplau (1909-1999) (van Betten \& Moriarty, 2004). Of the various ways that our lives and society have changed, for healthcare professionals and nurses in particular, modern medications have had an enormous impact. Certainly the development of extremely effective medications has made it possible for people to live long, fulfilling lives with chronic severe illnesses, to include mental illnesses. However, on some level, the modernization of medicine and pharmacology has been detrimental to the nursing profession. Nonetheless, mental health recovery as a philosophy and ideology, offers a potentially significant place for nursing, since the foundations of nursing are rooted in uniquely special, care-giving relationships between people. While we cannot simply go back in time as a profession, we can refocus our attention on being in healing relationships with people, something that has historically been a strength in nursing.

Therapeutic relationship. There is hardly a psychiatric mental health nurse who does not know of Hildegard Peplau and her Interpersonal Relations Theory. For Peplau, the relationship between nurse and patient is considered the therapeutic intervention, in and of itself (Stockmann, 2005). Implicitly, as with all traditional therapeutic modalities, the clinician is viewed as the expert and therefore, holds a position of power over the patient. In the context of mental health recovery, the power in the relationship between clinician and patient is shifting toward a more egalitarian model. 


\section{Mental Health Recovery and Power Relations}

During the course of reviewing the literature pertaining to mental health recovery for this research study, the quintessential article entitled The Recovery Model: Discourse Ethics and the Retrieval of the Self, authored by Joseph A. Fardella, explicitly solidified the philosophical underpinnings of mental health recovery, unlike any other. Fardella (2008) wrote:

The recovery model is different from other mental health reform movements in that it directly reflects the views of individuals who have, or continue to experience, the symptoms of mental illness. However, in addition to reflecting the emerging voice of previously "subjugated" or ignored individuals, the recovery model also represents a conjuncture of larger ethical, political and emancipatory interests. Just as the paternalistic and segregationist mental health reforms of the nineteenth century reflected traditional Victorian moral concerns and the development of twentieth century technical and professional interventions represented the dominance of scientific method and expert culture, so too does the recovery model reflect the larger challenges to "modernity" embodied in critical forms of postmodern thought, particularly those of Foucault. (p. 115)

Insight from Foucault's philosophy regarding power relations provided a strong foundation for Fardella's interpretation of the recovery model.

Egalitarian verses non-egalitarian relationships. In terms of power relations, the traditional therapeutic relationship puts the clinician in a position of power over the patient. In this non-egalitarian relationship, the clinician essentially assumes responsibility and possesses the expectation that the patient's/client's health will improve 
because of what the clinician says or does. While the health condition of the client may change for the better, a non-egalitarian relationship is incongruent with the type of relationship that reduces self-stigma and facilitates personal empowerment. Fardella (2008) explains:

For the recovery model, the subject must consciously recognize herself as an agent of choice; she must realize her potential in the reflective process of freely choosing goals that increase her prospects for human growth and development. Although acknowledging that the symptoms of mental illness may severely limit an individual's possibilities for human well being and growth, the recovery model nonetheless emphasizes the importance of affirming the person's capabilities and strengths. ... At the same time as the recovery model promotes a reflective process of personal growth and recovery, it also encourages clients to make morally responsible decisions concerning the ways that they identify, evaluate and act upon self-actualizing choices. As such, the recovery model encourages the subject to develop an ethical self, a self that attempts to understand and realize her possibilities for recovery in relation to the "other's" point of view or situation. In this way, the recovery model includes an ethic of shared care, which attempts to give attention to the views of those people, whether professionals, family members, or friends who may support or oppose the recovery oriented choices made by the client. Consequently, the recovery model promotes ethical relations in which the subject attempts to define her process of recovery in collaboration with other interested and potentially affected parties. (p.117) 
As such, a significant paradigm shift is essential within the context of mental health recovery. An egalitarian type of interpersonal relationship could be termed a healing relationship rather than therapeutic relationship. We have to shift the power within the interpersonal relationship from the clinician to the client, in order to equalize the power relations between them. This, I propose is a very relevant challenge for nursing science.

\section{Conclusion}

This research study began with the overall purpose to examine the relationship between self-stigma and personal empowerment among people who have severe mental illness. The results showed that there is an inverse relationship between self-stigma and personal empowerment. While this data is valuable, its relevance exists within the philosophical and theoretical framework of mental health recovery. The concepts and theoretical underpinnings of mental health recovery have been presented and explained within the context of this dissertation. As stated in the beginning, it was the intention of the researcher to understand the relationship between these concepts, in order to develop a theoretical framework on which to build more advanced nursing science pertaining to mental health recovery. During the process of conducting an exhaustive literature review for this study, a broader significance was realized. A heuristic compilation of relevant existing theories lending itself to the development of a mid-range theory of healing relationships will be the focus of future research studies. 


\section{References}

Andrews, A. B., Motes, P. S., Floyd, A., Flerx, V. C., \& Fede, A. L. (2005). Building evaluation capacity in community-based organizations: reflections of an empowerment evaluation team. Journal of Community Practice, 13(4), 85-104. doi:10.1300/J125v13n04_06

Anthony, W. A. (1993). Recovery from mental illness: The guiding vision of the mental health service system in the 1990s. Psychosocial Rehabilitation Journal, 16(4), 11.

Baker, P., \& Buchanan-Barker, P. (2004). Beyond empowerment: Revering the story teller. Mental Health Practice, 7(5), 18-20.

Bledsoe, S. E., Lukens, E., Onken, S., Bellamy, J. L., \& Cardillo-Geller, L. (2008). Mental Illness, Evidence-Based Practice, and Recovery: Is There Compatibility between Service-User-Identified Recovery-Facilitating and -Hindering Factors and Empirically Supported Interventions? Best Practice in Mental Health: An International Journal, 4(2), 34-58.

Brown, L. D., Shepherd, M. D., Merkle, E. C., Wituk, S. A., \& Meissen, G. (2008). Understanding how participation in a consumer-run organization relates to recovery. American Journal of Community Psychology, 42(1/2), 167-178. doi $10.1007 / \mathrm{s} 10464-008-9184-\mathrm{X}$

Caltaux, D. (2002). Internalized stigma - a barrier to recovery. New Zealand Journal of Occupational Therapy, 49(1), 25-27. 
Corrigan, P. W., Faber, D., Rashid, F., \& Leary, M. (1999). The construct validity of empowerment among consumers of mental health services. Schizophrenia Research, 38(1), 77-84.

Corrigan, P. W., \& Watson, A. (2002). The paradox of self-stigma and mental illness. Clinical Psychology: Science and Practice, 9(1), 35-53.

Corrigan, P. W. (2004). Enhancing personal empowerment of people with psychiatric disabilities. American Rehabilitation, 28(1), 10-21.

Corrigan, P. W., \& Calabrese, J. D. (2005). Strategies for assessing and diminishing selfstigma. On the stigma of mental illness: Practical strategies for research and social change. (pp. 239-256). Washington, DC US: American Psychological Association.

Corrigan, P. W., \& Kleinlein, P. (2005). The impact of mental illness stigma. On the stigma of mental illness: Practical strategies for research and social change. (pp. 11-44). Washington, DC US: American Psychological Association.

Corrigan, P. W., Watson, A. C., \& Barr, L. (2006). The self-stigma of mental illness: Implications for self-esteem and self-efficacy. Journal of Social \& Clinical Psychology, 25(8), 875-884.

Crane-Ross, D., Lutz, W. J., \& Dee, R. (2006). Consumer and case manager perspectives of service empowerment: Relationship to mental health recovery. Journal of Behavioral Health Services \& Research, 33(2), 142-155.

Deegan, P. E. (1997). Recovery and empowerment for people with psychiatric disabilities. Social Work in Health Care, 25(3), 11-24. 
Dixon, L., Lucksted, A., Stewart, B., Burland, J., Brown, C. H., Postrado, L., et al. (2004). Outcomes of the peer-taught 12-week family-to-family education program for severe mental illness. Acta Psychiatrica Scandinavica, 109(3), 207-215.

Falk-Rafael, A. R. (2001). Empowerment as a process of evolving consciousness: A model of empowered Caring. Advances in Nursing Science, 24(1), 1.

Fardella, J. (2008). The recovery model: Discourse ethics and the retrieval of the self. Journal of Medical Humanities, 29(2), 111-126. doi 10.1007/s10912-008-9054-4

Finfgeld-Connett, D. (2008). Qualitative convergence of three nursing concepts: Art of nursing, presence and caring. Journal of Advanced Nursing, 63(5), 527-534. doi: $10.1111 / \mathrm{j} .1365-2648.2008 .04622 . \mathrm{x}$

Fisher, D. B. (1994 a). A new vision of healing as constructed by people with psychiatric disabilities working as mental health providers. Psychosocial Rehabilitation Journal, 17(3), 67-81.

Fisher, D. B. (1994 b). Health care reform based on an empowerment model of recovery by people with psychiatric disabilities. Hospital \& Community Psychiatry, 45(9), 913-915.

Fisher, D. B. (2003). People are more important than pills in recovery from mental disorder. Journal of Humanistic Psychology, 43(2), 65.

Frain, M. P., Tschopp, M. K., \& Bishop, M. (2009). Empowerment variables as predictors of outcomes in rehabilitation. Journal of Rehabilitation, 75(1), 27-35. doi: $10.1111 / \mathrm{j} .1365-2850.2009 .01418 . \mathrm{x}$

Fulton, Y. (1997). Nurses' views on empowerment: A critical social theory perspective. Journal of Advanced Nursing, 26(3), 529-536. 
Fung, K. M. T., Tsang, H. W. H., \& Corrigan, P. W. (2008). Self-stigma of people with schizophrenia as predictor of their adherence to psychosocial treatment. Psychiatric Rehabilitation Journal. doi: 10.2975/32.2.2008.95.104

Fung, K. M. T., Tsang, H. W. H., Corrigan, P. W., Lam, C. S., \& Cheng, W. (2007). Measuring self-stigma of mental illness in China and its implications for recovery. International Journal of Social Psychiatry, 53(5), 408-418. doi: $10.1177 / 0020764007078342$

Gallo, K. M. (1994). First person account: Self-stigmatization. Schizophrenia Bulletin, $20(2), 407-410$.

Gastmans, C. (1998). Interpersonal relations in nursing: a philosophical-ethical analysis of the work of Hildegard E. Peplau. Journal of Advanced Nursing, 28(6), 13121319.

Green, C. A., Polen, M. R., Janoff, S. L., Castleton, D. K., Wisdom, J. P., Vuckovic, N., et al. (2008). Understanding how clinician-patient relationships and relational continuity of care affect recovery from serious mental illness: STARS study results. Psychiatric Rehabilitation Journal, 32(1), 9-22. doi: $10.2975 / 32.1 .2008 .9 .22$

Greene-Shortridge, T. M., Britt, T. W., \& Andrew, C. (2007). The stigma of mental health problems in the military. Military Medicine, 172(2), 157-161.

Hansson, L., \& Björkman, T. (2005). Empowerment in people with a mental illness: reliability and validity of the Swedish version of an empowerment scale. Scandinavian Journal of Caring Sciences, 19(1), 32-38. 
Jensen, L. W., \& Wadkins, T. A. (2007). Mental health success stories: Finding paths to recovery. Issues in Mental Health Nursing, 28(4), 325-340. doi:

$10.1080 / 01612840701244086$

Kroska, A., \& Harkness, S. K. (2006). Stigma sentiments and self-meanings: Exploring the modified labeling theory of mental illness. Social Psychology Quarterly.

Linhorst, D. M., Hamilton, G., Young, E., \& Eckert, A. (2002). Opportunities and barriers to empowering people with severe mental illness through participation in treatment planning. Social Work, 47(4), 425-434.

Link, B. G., Struening, E., Cullen, F. T., Shrout, P. E., \& Dohrenwend, B. P. (1989). A modified labeling theory approach to mental disorders: An empirical assessment. American Sociological Review.

Lundberg, B., Hansson, L., Wentz, E., \& Björkman, T. (2008). Stigma, discrimination, empowerment and social networks: a preliminary investigation of their influence on subjective quality of life in a Swedish sample. International Journal of Social Psychiatry, 54(1), 47-55. doi: 10.1177/0020764007082345

Mancini, M. A. (2007). A qualitative analysis of turning points in the recovery process. American Journal of Psychiatric Rehabilitation, 10(3), 223-244. doi:

$10.1080 / 15487760701508359$

Maslow, A. H. (1943). A theory of human motivation. Psychological Review, 50(4), 370396.

Masterson, S., \& Owen, S. (2006). Mental health service user's social and individual empowerment: Using theories of power to elucidate far-reaching strategies. Journal of Mental Health, 15(1), 19-34. doi: 10.1080/09638230500512714 
McCubbin, M. (2001). Pathways to health, illness and well-being: From the perspective of power and control. Journal of Community \& Applied Social Psychology, 11(2), 75-81. doi: $10.1002 /$ casp. 622

NIH Regulations and Ethical Guidelines (2005). Title 45 CFR Part Code of Federal Regulations Title 45 Public Welfare Department of Health and Human Services Part 46 Protection of Human Subjects. Retrieved from http://ohsr.od.nih.gov/guidelines/45cfr46.html\#46.102(i)

National Institute of Mental Health (NIMH) (2010). Prevalence of Serious Mental Illness Among U.S. Adults by Age, Sex, and Race. Retrieved from http://www.nimh.nih.gov/statistics/SMI_AASR.shtml

Padgett, D. K., \& Henwood, B. F. (2009). Obtaining large-scale funding for empowerment-oriented qualitative research: A report from personal experience. Qualitative Health Research, 19(6), 868-874. doi: 10.1177/1049732308327815

Perese, E. F. (2007). Stigma, poverty, and victimization: roadblocks to recovery for individuals with severe mental illness. Journal of the American Psychiatric Nurses Association, 13(5), 285-295. doi: 10.1177/1078390307307830

Roberts, G., \& Wolfson, P. (2004). The rediscovery of recovery: open to all. Advances in Psychiatric Treatment, 10(1), 37-37.

Rogers, E. S., Chamberlin, J., Ellison, M. L., \& Crean, T. (1997). A consumerconstructed scale to measure empowerment among users of mental health services. Psychiatric Services, 48(8), 1042-1047.

Rogers, E. S., Teague, G. B., Lichenstein, C., Campbell, J., Lyass, A., Chen, R., et al. (2007). Effects of participation in consumer-operated service programs on both 
personal and organizationally mediated empowerment: Results of multisite study. Journal of Rehabilitation Research \& Development, 44(6), 785-799. doi:

10.I682/JRRD.2006.10.0125

Rüsch, N., Angermeyer, M. C., \& Corrigan, P. W. (2005). Mental illness stigma: Concepts, consequences, and initiatives to reduce stigma. European Psychiatry, 20(8), 529-539. doi:10.1016/j.eurpsy.2005.04.004

Rüsch, N., Lieb, K., Bohus, M., \& Corrigan, P. W. (2006). Self-stigma, empowerment, and perceived legitimacy of discrimination among women with mental illness. Psychiatric Services, 57(3), 399-402.

SAMHSA (2006). National Consensus Statement on Mental Health Recovery. Retrieved from http://mentalhealth.samhsa.gov/publications/allpubs/sma05-4129/.

Schiff, A. C. (2004). Recovery and mental illness: Analysis and personal reflections. Psychiatric Rehabilitation Journal, 27(3), 212-218.

Sells, D., Borg, M., Marin, I., Mezzina, R., Topor, A., \& Davidson, L. (2006). Arenas of recovery for persons with severe mental illness. American Journal of Psychiatric Rehabilitation, 9(1), 3-16. doi 10.1080/15487760500339402

Shanley, E., \& Jubb-Shanley, M. (2007). The recovery alliance theory of mental health nursing. Journal of Psychiatric \& Mental Health Nursing, 14(8), 734-743.

Smith, M. K. (2000). Recovery from a severe psychiatric disability: Findings of a qualitative study. Psychiatric Rehabilitation Journal, 24(2), 149-158.

Stockmann, C. (2005). A literature review of the progress of the psychiatric nurse-patient relationship as described by Peplau. Issues in Mental Health Nursing, 26(9), 911919. doi: $10.1080 / 01612840500248197$ 
Straughan, H., \& Buckenham, M. (2006). In-Sight: An evaluation of user-led, recoverybased, holistic group training for bipolar disorder. Journal of Public Mental Health, 5(3), 29-43.

Tal, A., Roe, D., \& Corrigan, P. W. (2007). Mental illness stigma in the Israeli context: deliberations and suggestions. International Journal of Social Psychiatry, 53(6), 547-563. doi: $10.1177 / 0020764007082346$

Till, U. (2007). The values of recovery within mental health nursing. Mental Health Practice, 11(3), 32-36.

UCSD Human Research Protection Program. (n.d.). Decision making capacity guidelines. Retrieved from http://irb.ucsd.edu/decisional.shtml van Betten, P. T., \& Moriarty, M. (2004). Nursing illuminations: a book of days. St. Louis, Missouri: Elsevier Mosby, Inc.

Verhaeghe, M., Bracke, P., \& Bruynooghe, K. (2008). Stigmatization and self-esteem of persons in recovery from mental illness: the role of peer support. International Journal of Social Psychiatry, 54(3), 206-218. doi: 10.1177/0020764008090422

Vogel, D. L., Wade, N. G., \& Haake, S. (2006). Measuring the self-stigma associated with seeking psychological help. Journal of Counseling Psychology, 53(3), 325 337. doi: $10.1037 / 0022-0167.53 .3 .325$

Watson, A. C., Corrigan, P., Larson, J. E., \& Sells, M. (2007). Self-Stigma in people with mental illness. Schizophrenia Bulletin, 33(6), 1312-1318. doi:10.1093/schbul/sbl076

Watson, A. C., \& Larson, J. E. (2006). Personal responses to disability stigma: from selfstigma to empowerment. Rehabilitation Education, 20(4), 235-246. 
Wehmeyer, M. L. (2004). Self-determination and the empowerment of people with disabilities. American Rehabilitation, 28(1), 22-29.

Werner, P., Aviv, A., \& Barak, Y. (2008). Self-stigma, self-esteem and age in persons with schizophrenia.

Wong-McDonald, A. (2007). Spirituality and psychosocial rehabilitation: Empowering persons with serious psychiatric disabilities at an inner-city community program. Psychiatric Rehabilitation Journal, 30(4), 295-300. doi:

$10.2975 / 30.4 .2007 .295 .300$ 


\section{APPENDIX A}

\section{Diane Hickman}

Subject:

Attachments:
FW: Self-stigma of Mental Illness and Personal Empowerment Research EMPSCORE.DOC

--.--Original Message--.-.-

From: E. Sally Rogers [mailto:erogers@bu.edu]

Sent: Tuesday, November 17, 2009 2:57 PM

To: Diane Hickman

Cc: Center for Psychiatric Rehabilitation; Emily Green

Subject: Re: Self-stigma of Mental Illness and Personal Empowerment Research

Diane,

Attached you will find instructions for scaling the Empowerment measure, which you requested a few weeks ago. (Sorry for the delay in responding. Sometimes emails slip through despite my best intentions!)

Let me know if you have any questions.

Thanks.

Sally Rogers

Diane Hickman wrote:

Dear Dr. Rogers,

During the past year I have been working on my dissertation proposal, utilizing your Making Decisions Empowerment (MDE) scale, for which I received your permission. I' $m$ writing to inform you that rather than recruiting participants from the VA San Diego Healthcare System, I will be recruiting participants from adult residential facilities for people who have severe mental illness within the San Diego County area. These facilities are board \& cares housing, independent living facility housing, and a transitional housing facility. Occupants are both veterans and non-veterans. This is the only significant change that l've made since our prior e-mail communication approximately one year ago.

I have a question about the scale itself. I want to be absolutely sure I will be calculating the scores accurately. According to your article "Effects of participation in consumer-operated service programs on both personal and organizationally mediated empowerment: Results of multisite study" (2007), 


\begin{abstract}
APPENDIX A
"The Making Decisions Empowerment (MDE) scale is a 28-item instrument designed to measure subjective feelings of empowerment in which respondents rate statements on a 4-point scale (1 - "Strongly agree" and 4 = "Strongly Disagree") [25]. "/Most of the items indicate greater empowerment; individual scale values for these items are reversed (subtracted from 5) so that higher scores are more favorable, and responses are then summed across items $/{ }^{*}$." From this $I$ understand that the scores for particular items are subtracted from 5.
\end{abstract}

Could you please provide me with more explicit directions for calculated the MDE scale scores? Your help with this is greatly appreciated.

Thank you,

Diane

Diane Fischer Hickman

C: $619-997-0220$

$\mathrm{H:}$ 858-270-6158

e: dhickman@san.rr.com

e: dfhickman@gmail.com

--.--Original Message--.--

From: E. Sally Rogers [mailto:erogers@bu.edu]

Sent: Wednesday, October 22, 2008 8:16 AM

To: Diane Hickman

Cc: egreen Emily Green; Center for Psychiatric Rehabilitation

Subject: Re: Self-stigma of Mental Illness and Personal Empowerment Research

Diane,

Thank you for your description of how you intend to use the scale. You have our permission to use the scale as you describe.

Let me know if you have additional questions.

Sally Rogers

Diane Hickman wrote:

Dear Dr. Rogers,

Thank you for your prompt response. The following is a little more information about me and a basic description of my research interest. 


\section{APPENDIX A}

I am a PhD student in the PhD in Nursing program at the University of San Diego (USD) and a Psychiatric Mental Health Clinical Nurse Specialist at the VA San Diego Healthcare System as a nurse case manager in a VA program entitled Mental Health Intensive Case Management (MHICM). I have been interested in mental health recovery for many years and have a particular inclination to study barriers to mental health recovery. My work with veterans who have a serious, severe, persistent mental illnesses has revealed to me the significance of self-stigma and lack of personal empowerment among my clients, which appears to be a critical barrier to their mental health recovery process. I have become familiar with the concept of self-stigma through the work of Dr. Patrick Corrigan. In his most recent article with Dr. Amy Watson, et al, entitled Self-Stigma in People with Mental Illness, the following statement percolated my profound interest in the concept or proposition that empowerment and self-stigma are opposite poles on a continuum. Dr. Watson, Dr. Corrigan et al wrote:

Research on empowerment in persons with mental illness has illustrated alternative responses. This research represents empowerment and self-stigma as opposite poles on a continuum.23-25 At the negative end of the continuum are people who are unable to overcome negative expectations and stereotypes about mental illness. They have low self-esteem and little confidence in their future success. These are the self-stigmatized. At the positive end are persons with psychiatric disability who, despite this disability, have positive selfesteem and are not significantly encumbered by public stigma. Instead, they seem to be energized by the stigma to empowerment.26,27 I am thoroughly intrigued by the concept or proposition that empowerment and self-stigma are opposite poles on a continuum and I would like to explore this dichotomy further.

For my doctoral dissertation I am proposing to do a descriptive study that will examine the relationship between self-stigma and personal empowerment. My hypothesis is that there is an inverse relationship between self-stigma and personal empowerment, such that a high degree of self-stigma will correlate with a low degree of personal empowerment and a low degree of self-stigma will correlate with a high degree of personal empowerment. Dr. Corrigan has provided me with his Self-Stigma of Mental Illness Scale. Through my literature review related to self-stigma and empowerment I became aware of your Consumer Constructed Scale to Measure Empowerment. These two instruments seem to be the best suited to measure self-stigma and personal empowerment.

I am considering administering both instruments to a cohort of veterans, as described above to statistically analyze the correlation between the two characteristics, self-stigma and personal empowerment. 


\section{APPENDIX A}

Similar to your inclusion and exclusion criteria for your research as described in your article, Effects of participation in consumer-operated service programs on both personal and organizationally mediated empowerment: Results of multisite study_, participants in my research will be individuals who have a DSM Axis 1 and/or Axis 2 diagnosis that constituted a serious mental illness, such as schizophrenia, schizoaffective disorder, or a major depressive disorder. In addition to having a serious and persistent mental illness, the participants will be required to be actively involved with a traditional mental health provider at the VA San Diego Healthcare System, for at least 12 months before study entry and be able to provide full and informed consent. An exclusion criterion will be an inability to participate in the research interviews.

My rationale for studying this population of people who have a serious mental illness is simply my accessibility to these people, by virtue of employment as a psychiatric mental health nurse case manager at the VA San Diego Healthcare System, plus my status as doctoral student in the PhD in Nursing program at the University of San Diego, which is closely affiliated with the VA San Diego Healthcare System.

I would sincerely appreciate any information and guidance that you can provide me, as I pursue my research regarding self-stigma and personal empowerment, as described above.

Thanks again for your interest in my work and willingness to assist me with my research.

Diane

Diane Hickman

C: 619-997-0220

H: 858-270-6158

e: dhickman@san.rr.com <mailto:dhickman@san.rr.com>

-.-.--Original Message-...-

From: E. Sally Rogers [mailto:erogers@bu.edu]

Sent: Friday, October 03, 2008 8:18 AM

To: Diane Hickman

Cc: Center for Psychiatric Rehabilitation

Subject: Re: Self-stigma of Mental Illness and Personal Empowerment Research Diane, 


\section{APPENDIX A}

Attached is a copy of the scale for your perusal as well as a recent publication that used the scale.

If you could tell me how you would intend to use the scale (what population at the VA and what kind of study), I can grant permission for its use.

I can also send additional material by regular mail if you would like. Just let me know where it should be sent.

Thank you for your interest in the work of the Center.

Sally Rogers

Diane Hickman wrote:

Dear Dr. Rogers,

My name is Diane Hickman. I am a PhD student in the PhD in Nursing program at the University of San Diego (USD). I am a Psychiatric Mental Health Clinical Nurse Specialist and I work at the VA San Diego Healthcare System as a nurse case manager in a VA program entitled Mental Health Intensive Case Management (MHICM). My professional and academic work has led me to your work about "personal empowerment."

During my dissertation literature review I located your article entitled_A consumer-constructed scale to measure empowerment among users of mental health services_, (Rogers, E. S., Chamberlin, J., Ellison, M. L., \& Crean, T. (1997). A consumer-constructed scale to measure empowerment among users of mental health services.

/Psychiatric Services, 48/, 1042-1047.).

I would greatly appreciate information about how to obtain a copy of this instrument and permission to use it in my research.

Very respectfully,

Diane

Diane Hickman

C: $619-997-0220$

H: 858-270-6158

e: dhickman@san.rr.com 


\section{APPENDIX B}

\section{Diane Hickman}

Subject:

FW: RE: Self-stigma of Mental Illness Scale

-..--Original Message-...-.

From: Patrick William Corrigan [mailto:corrigan@iit.edu]

Sent: Saturday, September 13, 2008 8:19 PM

To: Diane Hickman

Cc: psychrehab-admin@iit.edu

Subject: Re: RE: Self-stigma of Mental Illness Scale

Jen

can you send Diane a copy of the SSMIS

Pat Corrigan

Illinois Institute of Technology

3424 S State Street, first floor

Chicago, IL 60626

voice $312567-6751$

fax $312567-6753$

-...- Original Message

From: Diane Hickman <dhickman@san.rr.com>

Date: Saturday, September 13, 2008 8:48 pm

Subject: RE: Self-stigma of Mental Illness Scale

To: 'Patrick William Corrigan' <corrigan@iit.edu>

Thanks for your reply. No I have not been able to get a copy of the measure. I have found your article Self-Stigma in People With Mental IIIness, and the abstract. I have not yet obtain a copy of the full journal article.

Diane

-----Original Message-----

From: Patrick William Corrigan [mailto:corrigan@iit.edu]

Sent: Saturday, September 13, 2008 5:16 PM

To: Diane Hickman

Subject: Re: Self-stigma of Mental Illness Scale

have you been able to get a copy of the measure the best thing I have written on it are papers with Amy Watson, one in Schizophrenia Bulletin and a more recent manuscript 


\section{APPENDIX B}

regards

Pat Corrigan

Iltinois Institute of Technology

3424 S State Street, first floor

Chicago, IL 60626

voice $312567-6751$

fax $312567-6753$

....- Original Message ......

From: Diane Hickman <dhickman@san.rr.com>

Date: Saturday, September 13, 2008 5:45 pm

Subject: Self-stigma of Mental Illness Scale

To: Patrick Corrigan <corrigan@iit.edu>

Dear Dr. Corrigan,

My name is Diane Hickman. I am a PhD student in the PhD in Nursing program at the University of San Diego (USD). I am a Psychiatric, Mental Health Clinical Nurse Specialist and I work at the VA San Diego Healthcare System as a nurse case manager in a VA program entitled Mental Health Intensive Case Management (MHICM). My professional and academic work has led me to your work about "self-stigma." For my dissertation, I have decided to study the concept of "Self-stigma as a Barrier to Mental Health Recovery." At this point in my dissertation process, I have narrowed my research question to be, "Is selfstigma a barrier to mental health recovery among veterans who have a DSM IV Axis 1 diagnosis of Bipolar 1 Disorder, who are receiving psychiatric mental health services at VA San Diego Healthcare System?"

I was excited to find out about the Self-stigma of Mental Illness Scale. I would sincerely appreciate any information and advice you can give me about this instrument in general as well as its possible appropriateness for use in my dissertation research.

Very respectfully,

Diane Hickman

Diane Hickman

C: $619-997-0220$

$\mathrm{H:} \mathrm{858-270-6158}$

e: dhickman@san.rr.com 